\title{
Functionalized Exfoliated Graphene Oxide as Supercapacitor Electrodes
}

\author{
Prasanna Karthika, Natarajan Rajalakshmi*, Kaveripatnam S. Dhathathreyan
}

Centre for Fuel Cell Technology, International Advanced Research Centre for Powder Metallurgy and New Materials, IITM Research Park, Chennai, India.

Email: *lakshmiraja2003@yahoo.com

Received July $31^{\text {st }}, 2012$; revised August $31^{\text {st }}$, 2012; accepted September $16^{\text {th }}, 2012$

\begin{abstract}
Functionalized exfoliated graphene oxide (EGO) for supercapacitor electrodes have been synthesized by simple chemical methods from the exfoliated graphite (EG) as precursor. Structural and morphological characterizations of EGO have been carried out using X-Ray Diffraction (XRD), Scanning Electron Microscopy (SEM), FTIR and Raman spectroscopy. Electrochemical performance of these electrodes has been investigated using cyclic voltammetry, galvanostatic charge-discharge, and electrochemical impedance spectroscopy. The fabricated supercapacitor gave a specific capacitance of $146 \mathrm{Fg}^{-1}$ and energy density of $20 \mathrm{Wh} \cdot \mathrm{kg}^{-1}$ for a highly oxidized sample with more functional groups compared to pure, lower level oxidized and reduced samples. The single and multi layered graphene oxide sheets produced by this method have a lower degree of agglomeration. We found that the graphene oxide with functional oxygen groups of quinine type enhances the capacitance compared to other oxygen functional groups.
\end{abstract}

Keywords: Graphene; Supercapacitor; Functionalization; Exfoliation; Carbon

\section{Introduction}

Supercapacitors based on electrochemical double layer capacitance (EDLC) are electrical energy storage devices that store and release energy by charge separation at the electrochemical interface between an electrode and an electrolyte [1]. These capacitors have an extremely high energy density compared to conventional dielectric capacitors, as the energy stored is inversely proportional to the thickness of the double layer and they are able to store a large amount of charge which can be delivered at much higher power ratings than rechargeable batteries. They can be used in a wide range of energy capture and storage applications and are used stand alone as the primary power source or in combination with batteries or fuel cells due to their advantages like high power capability, long life, a wide thermal operating range, low weight, flexible packaging, and low maintenance. In addition to the EDLCs another class of supercapacitor that is based on pseudocapacitance can also is employed, where the storage mechanism is based on faradic, and redox reactions occur using electrode materials such as electrically conducting polymers and metal oxides. Though the energy densities of pseudocapacitance based devices are greater than EDLCs, the phase changes within the electrode due to the faradic reaction limit their

*Corresponding author. lifetime and power density [2-4].

Supercapacitors use nanoporous electrodes based on carbon materials like VulcanXC, Acetylene Black, Carbon Nnaotubes etc., to store large amounts of charge on their high surface areas, and use the ions in electrolytes to carry charge into the pores. Their high power density makes them a potentially useful complement to batteries. However, ion transport through long, narrow channels still limits power and efficiency in these devices [5]. Various conducting polymers have also been widely studied as electrode materials for supercapacitors because of their high capacitance, easy production, and low cost. However, poor conductivity and weak flexibility of conducting polymers limit them from usage in high performance flexible supercapacitors.

Graphene, a two dimensional carbon material, has attracted much research attention due to several breakthroughs in fundamental research and for practical applications [6-18]. In contrast to the conventional high surface area materials, the effective surface area of graphene materials as capacitor electrode materials does not depend on the distribution of pores at solid state, which is different from the current supercapacitors fabricated with activated carbons and carbon nanotubes [19]. Graphene oxide, existing as individual layered sheets, can be an ideal electrode material as their graphene sides could be exposed to electrolyte with possibly high surface area 
and thus result in high specific capacitance. Chemically modified graphene exhibits numerous active edges and functional groups based on oxygen. It has good electrochemical and mechanical properties and find them suitable for energy storage devices [20-22]. Wang et al. [23] prepared a Freestanding and flexible graphene/polyaniline composite paper by an in situ anodic electropolymerization of polyaniline film on graphene paper, which showed a stable large electrochemical capacitance of 233 $\mathrm{Fg}^{-1}$, for flexible supercapacitors.

Composites made of Graphene nanosheet/carbon nanotube/polyaniline (GNS/CNT/PANI) via in situ polymerization has been studied by Yan et al. and they reported a high specific capacitance compared to pure PANI and CNT/PANI composite [24]. They also reported the improved cyclic stability as well as mechanical strength of the electrode during doping/dedoping processes and the degradation was found to be $6 \%$ after 1000 cycles compared to $52 \%$ and $67 \%$ for GNS/PANI and CNT/PANI composites. Kaempgen et al [25] reported a fully printable high performance supercapacitor based on thin films of singlewalled carbon nanotubes. The architecture involves the use of such carbonaceous materials for both the electrode and charge collector, and showed several advantages. VivekChand et al., studied the graphene material for supercapacitor application and reported a specific capacitance of $117 \mathrm{Fg}^{-1}$ in aqueous $\mathrm{H}_{2} \mathrm{SO}_{4}$ [16] and Meryl et al [19] reported a specific capacitance of 135 $\mathrm{Fg}^{-1}$ in aqueous electrolyte for a multilayered graphene material.

Graphene from graphite oxide has been mainly produced by the oxidation of graphite in the presence of strong acids and oxidants [26]. The level of oxidation can be varied on the basis of the method, like reaction conditions and the nature of precursor. Although extensive research has been done to reveal the chemical structure of graphene oxide, there is lot of debate in the literature with respect to synthesis by several methods and various morphologies. In addition, the effect of functionalization by the grafting of organic moities for supercapacitor application is very limited, although they contribute to pseudocapacitance. Though oxygen functional groups seem to enhance the wettability and capacitance value, not all the surface oxygen groups seem to contribute in the same way due to their nature. To develop an advanced supercapacitor device, an active electrode material with oxygen functional groups are required for enhanced capacitance. Herein, we report a simple process to synthesis the Exfoliated Graphene Oxide (EGO) at two different oxidation levels leading to different level of oxygen groups, (A and B) and Reduced Exfoliated Graphene Oxide (REGO) using gas based reduction, and fabricated supercapacitor devices using these as electrode materials and investigated their performance. The results reported here are based on pseudocapacitance and EDLC supercapacitor cells with exfoliated graphene oxide electrode material.

\section{Experimental}

\section{Synthesis of Exfoliated Graphene Oxide}

The Exfoliated graphene oxide was prepared by stirring $1 \mathrm{~g}$ of powdered exfoliated graphite (EG) flakes and 50 $\mathrm{mg}$ of sodium nitrate into $23 \mathrm{ml}$ of concentrated sulphuric acid. While maintaining vigorous agitation, $3 \mathrm{~g}$ of $\mathrm{KMnO}_{4}$ was added to the suspension kept in an ice bath. The rate of addition was controlled carefully to prevent the temperature of the suspension from exceeding $20^{\circ} \mathrm{C}$. The ice-bath was then removed and the temperature of the suspension was kept at $35^{\circ} \mathrm{C}$, where it is maintained for 30 minutes. After 20 minutes the mixture became pasty (brownish grey in color) with evolution of only a small amount of gas. At the end of 30 minutes, $50 \mathrm{ml}$ of water was slowly stirred into the paste, causing violent effervescence and a raise in temperature to $98^{\circ} \mathrm{C}$. The diluted suspension, brown in color, was maintained at this temperature for 15 minutes. The suspension was then further diluted with warm water and treated with $3 \% \mathrm{H}_{2} \mathrm{O}_{2}$ to reduce the residual permanganate and manganese dioxide to colorless soluble manganese sulfate. Upon treatment with the peroxide, the suspension turned bright yellow. The substance was washed copiously with water and dried overnight.

The exfoliated graphite (EG) were oxidized at two different levels with $23 \mathrm{ml}$ and $46 \mathrm{ml}$ of conc. $\mathrm{H}_{2} \mathrm{SO}_{4}$ respectively, and the sample is labeled as EGOA (exfoliated graphene oxide A) and EGOB (exfoliated graphene oxide B). The above samples were reduced at $300^{\circ} \mathrm{C}$ by passing hydrogen gas and the reduced samples were named as REGOA (reduced exfoliated graphene oxide A) and REGOB (reduced exfoliated graphene oxide B). All the samples were characterized by Powder XRD for structure analysis and by FTIR spectra for their functional groups. Perkin Elmer FTIR spectrometer using $\mathrm{KBr}$ pellet method in the wavenumber region 400 to $4500 \mathrm{~cm}^{-1}$ has been used for FTIR. The Raman spectra of EG, EGO were acquired to characterize the formation of graphene oxide, using Witec GnbH confocal Raman microscope with Ar ion laser at $514.5 \mathrm{~nm}$ using FTRaman spectrometer (FRA 106 Bruker) excited by 1064 $\mathrm{nm}$ laser. Scanning electron microscopy (SEM) observation has been performed in order to obtain information about the morphology of all the samples. The electrodes for capacitance measurement were fabricated by forming a paste of the EGO/REGO samples with a binder polytetrafluroethlene (PTFE). The paste was spread using a doctor blade and roll pressed uniformly onto a nickel mesh that serves as current collector. A standard three electrode cell was used to study the capacitance behavior 
of the EGO and REGO electrodes, with standard calomel electrode (SCE) as reference electrode and a Pt mesh as counter electrode. An aqueous solution of $1 \mathrm{M} \mathrm{KOH}$ was used as the electrolyte in all electrochemical experiments. Cyclic voltammograms in the range -0.9 to $0.6 \mathrm{~V}$ was taken at various scan rates for all the samples using a computerized potentiostat-galvanostat model Solartron analytical 1400 Cell Test System. Electrochemical impedance spectroscopy in the range $100 \mathrm{kHz}$ to $10 \mathrm{mHz}$ and Galvanostatic charge/discharge tests at $50 \mathrm{~mA} \cdot \mathrm{cm}^{-2}$ were also carried out using the same instrument to measure the impedance and the cycle life respectively.

\section{Results and Discussion}

\subsection{X-Ray Diffraction}

The XRD patterns shown in Figure 1 confirm the chemical oxidation of the exfoliated graphite and formation of graphene oxide sheets.

The initial exfoliated graphite shows the sharp diffracttion peak at $2 \theta=26.6$ with the corresponding d-spacing of $3.34 \AA$. The oxidation process results in the insertion of hydroxyl and epoxyl groups between the carbon sheets mainly on the centers while the carboxyl groups are inserted on the terminal and lateral sides of the sheets. The insertion of these groups leads to decrease in the van der Waals forces between the graphene sheets in the exfoliated graphene oxide. As shown in Figure 1, the XRD pattern of exfoliated graphene oxide shows another peak at $2 \theta=11.2$ with a d-spacing of $8.14 \AA$. This indicates that the distance between the graphene sheets has increased due to the insertion of interplanar groups. The 002 reflections in the sample EGO is broad suggesting that the samples are very poorly ordered along the stacking direction revealing that these samples comprise largely free graphene sheets.

\subsection{Raman Spectra}

The Raman spectrum provides the best signature of characterizing graphene, in that it is not only sensitive to the number of layers but also to dopant effects. The Raman spectra of the exfoliated graphite material and the oxidized graphene materials are as shown in Figure 2 showing the $G$ and $D$ peak due to the bond stretching of all pairs of $\mathrm{sp}^{2}$ atoms and the breathing modes of $\mathrm{sp}^{2}$ atoms in rings respectively.

The stiff and sharpened Raman G-band peak shows the electrochemical doping. The $\mathrm{G}$ band of exfoliated graphite and oxidized graphene oxide samples have the same shape and differ only in intensity. The numbers of stacked graphene layers were characterized using the position and shape of the 2D band around $2700 \mathrm{~cm}^{-1}$. The 2D band of monolayer graphene is sharp and symmetric. Equally important is that the ratio of intensities of the

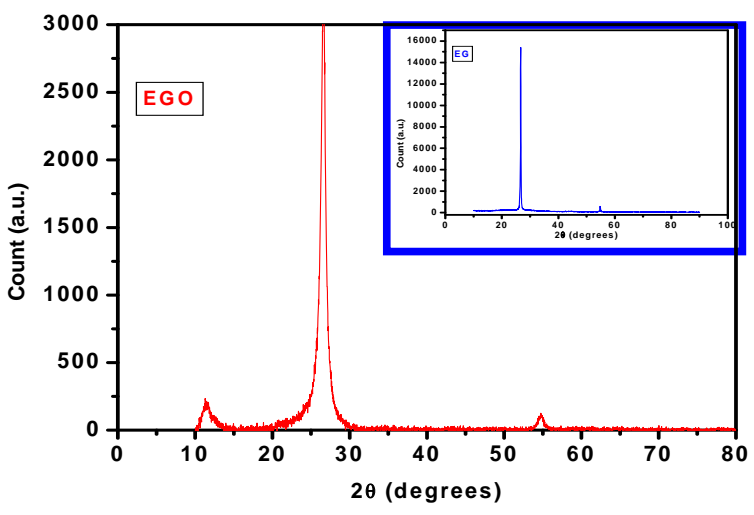

Figure 1. Powder XRD pattern of EG and EGO sample.

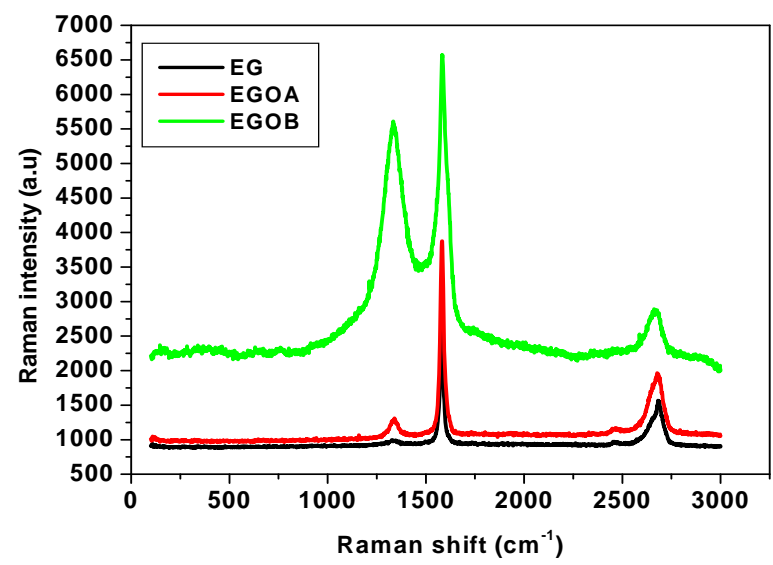

Figure 2. Raman spectra of EG and EGO samples.

Raman 2D and $\mathrm{G}$ band depends on doping. The intensity ratio of $\mathrm{G}\left(\mathrm{I}_{\mathrm{G}}\right)$ and $2 \mathrm{D}$ band $\left(\mathrm{I}_{2 \mathrm{D}}\right)$ for $\mathrm{EG}, \mathrm{EGOA}, \mathrm{EGOB}$ samples are calculated as $0.639,0.6758,1.946$ respectively revealing that the oxidized samples show both a mixture of single and multiple layers.

$\mathrm{D}$ band peaks are observed before and after doping, indicating that $\mathrm{H}_{2} \mathrm{SO}_{4}$ treatment is destructive to the chemical bonds of graphene. The decrease in $\mathrm{D}$ band intensity with increase in graphene thickness demonstrating that defects are more easily introduced into thinner graphene sheets. The increase in the D band intensity with increase in degree of oxidation reveals the disorder present in the sample, which can facilitate the easy trapping of ions from the electrolyte.

\subsection{FTIR Characterization}

The various functional groups that enhance the pseudo capacitance behavior of all the materials both oxidized and reduced were analyzed employing the FTIR spectra shown in Figure 3.

Exfoliated Graphene oxide consists of covalently attached oxygen containing groups such as hydroxyl, epoxy, carbonyl and carboxyl groups. Considering the structure of graphene oxide, it is generally accepted that 


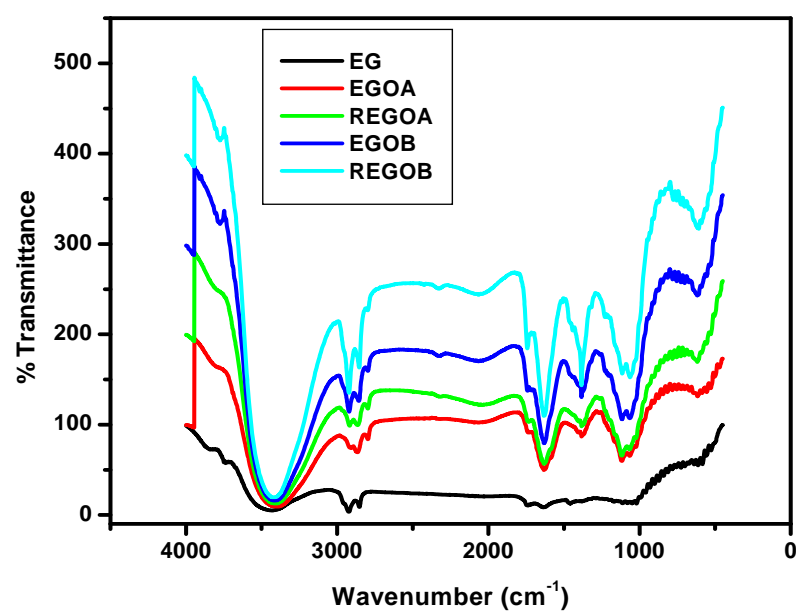

Figure 3. FT-IR spectra of oxidized and reduced EG samples.

the epoxy and $\mathrm{C}-\mathrm{OH}$ functional groups are attached above and below each carbon layer (the basal plane), while the $\mathrm{COOH}$ groups are bound to the edges of the basal planes. It has been reported [26-29] that the functional groups and heteroatoms on the carbon sheets improve the wettability of electrode due to increased number of hydrophilic polar sites and thus enhances the overall capacitance of the electrodes.

The difference in the transmission spectra can be observed between the oxidized and reduced samples due to various functional groups as shown in Figure 3. The broad envelope position around $3364 \mathrm{~cm}^{-1}$, due to $\mathrm{O}-\mathrm{H}$ stretching vibrations is almost absent in pure EG and is very pronounced in the reduced sample viz., REGOB. The CH stretching vibrations are found at $2900 \mathrm{~cm}^{-1}$ can be seen in all the samples. The $\mathrm{C}=\mathrm{O}$ stretching of $\mathrm{COOH}$ groups situated at edges of graphene oxide sheets is observed at $1726 \mathrm{~cm}^{-1}$. The $\mathrm{C}=\mathrm{C}$ peak at $1618 \mathrm{~cm}^{-1}$ corresponds to the $\mathrm{sp}^{2}$ character. The absorption at $1300 \mathrm{~cm}^{-1}$ may be attributed to the $\mathrm{C}-\mathrm{O}$ vibrations.

\subsection{SEM Characterization}

The surface morphology of the exfoliated graphite and the oxidized samples were analyzed from the SEM images, and are shown in Figures 4(a)-(d) for all the pure, oxidized and reduced samples.

At a low magnification, carpet morphology was observed for all exfoliated graphene oxide samples (Figure 4(b)). It can be seen that exfoliated graphite particles are worm like (Figure 4(a)) and graphite layers have been opened mostly. The SEM images of EGO samples resemble transparent and rippled silk waves (Figures 4(b) and (c)). The edges of the exfoliated graphene oxide sheets are crumpled due to the oxidation process (Figure 4(d)). Though EGO sheets still exists as aggregated and crumpled sheets closely associated with each other forming a

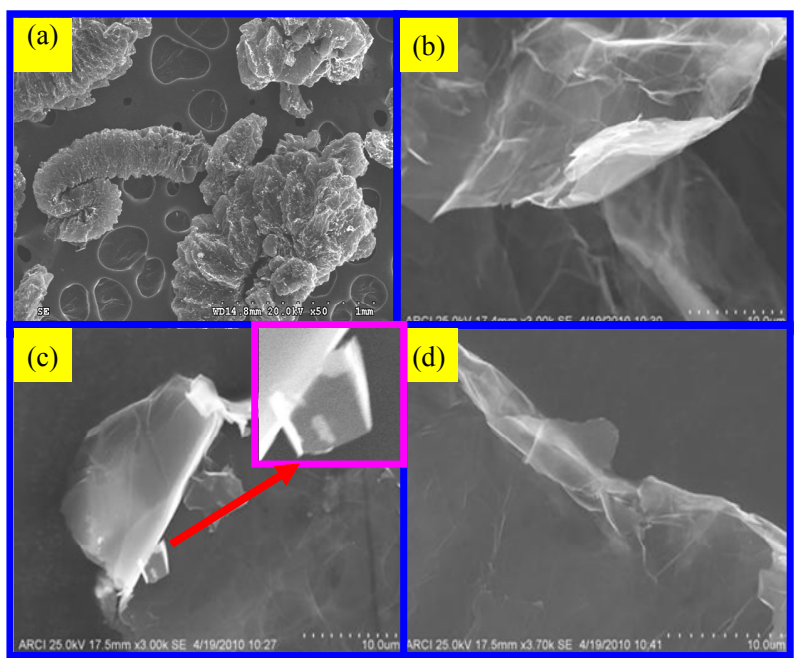

Figure 4. SEM images of pure EG and EGO samples.

continuum conducting network, these SEM images suggest that EGO has low degree of agglomeration. With increase in level of oxidation no significant change was detected except for the sharp edges being rounded off. The macro porous structure of these materials and the functional groups together increases the capacitance effect since the charge is stored throughout the bulk of the materials as well as at the electrode/electrolyte interface.

\subsection{Electrochemical Measurements}

Cyclic voltammetry measurements were conducted to test the performance of the sample after conditioning the electrodes by cycling several times at $5 \mathrm{~m} \cdot \mathrm{Vs}^{-1}$. Figure 5 shows the $\mathrm{CV}$ measured for the electrodes prepared using pure EG, oxidized (EGOA and EGOB) and reduced samples (REGOA and REGOB) respectively at scan rate of $5 \mathrm{mV} \cdot \mathrm{s}^{-1}$ and the $\mathrm{CV}$ of EGOB at different scan rates from 5 to $100 \mathrm{mV} \cdot \mathrm{s}^{-1}$ are given in Figure 6 .

Due to the internal resistance of the electrode, the shape is slightly distorted from rectangular and close to parallelogram, indicating that the main contribution to the capacitance is the charge and discharge of the double layer. The presence of various functional groups in the materials contributes in the form of pseudocapacitance, as can be seen from the anodic and corresponding cathodic peaks, from the redox reaction of surface functional groups. The increase in the current density with increase in level of oxidation can also be visualized from the CV profiles.

The capacitance decreases at higher scan rates for all the samples and also there exists lot of distortion in the $\mathrm{CV}$ spectrum. The distortion in the $\mathrm{CV}$ and the decreased capacitance at higher scan rates are mainly due to the increase in the inaccessible sites within the electrode. The specific capacitance of EG, EGOA, REGOA, EGOB and REGOB are 2.590, 31.8, 27.29, 101.013 and 43.466 


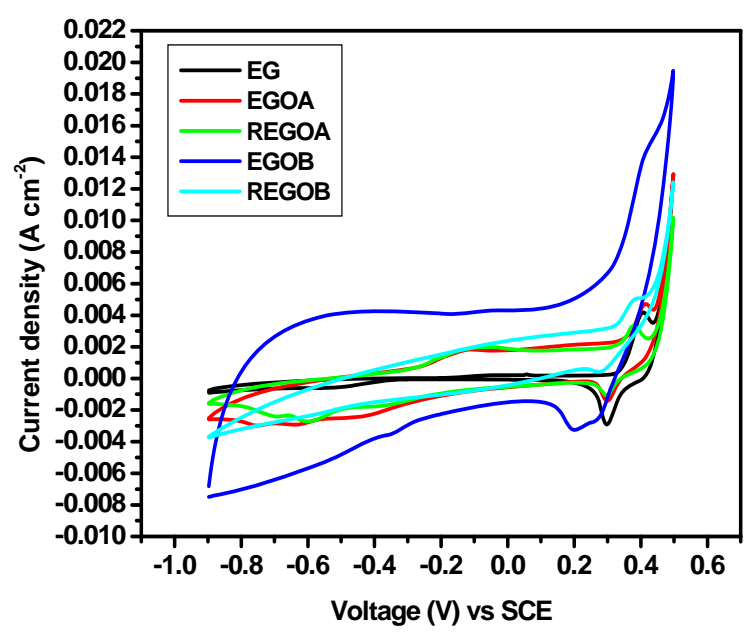

Figure 5. Cyclic voltammograms of EG, EGOA, REGOA, EGOB, and REGB at scan rate of $5 \mathrm{mV} \cdot \mathrm{s}^{-1}$.

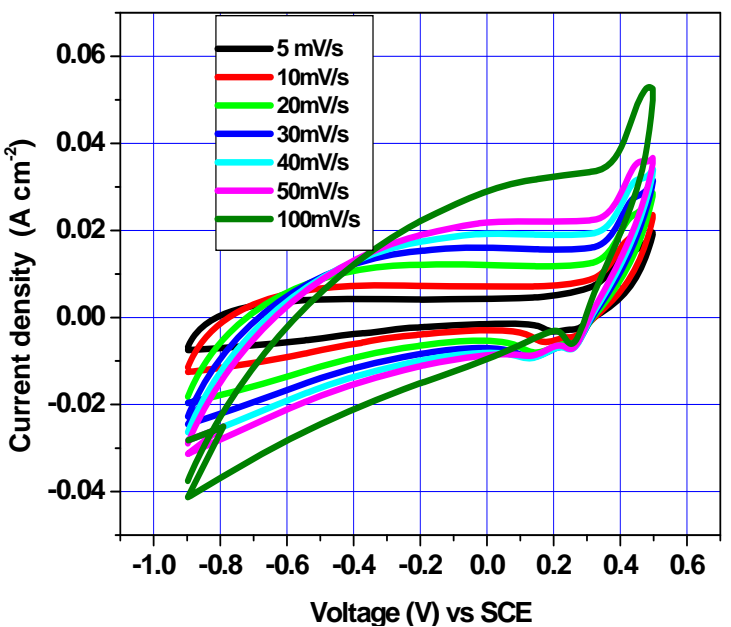

Figure 6. Cyclic voltammograms of EGOB electrode with increase in scan rate from 5 to $100 \mathrm{mV} \cdot \mathrm{s}^{-1}$.

$\mathrm{Fg}^{-1}$ respectively as calculated from $\mathrm{CV}$ at a scan rate of $5 \mathrm{~m} \cdot \mathrm{Vs}^{-1}$. While comparing the CVs of all the electrodes prepared, the specific capacitance of the material increases with the degree of oxidation or in other words the oxygen functionalities, pseudo capacitance contribution is more concentrated. The variation of specific capacitance with scan rates is shown in Figure 7.

The voltammograms also exhibit that the induced current is as increasing function of the oxidation level, indicating the increase of capacitance upon oxidation.

\subsection{Impedance Measurements}

Impedance plots recorded for all the electrodes in frequency range $100 \mathrm{KHz}$ to $10 \mathrm{mHz}$ for the electrodes are shown in Figure 8.

The Nyquist plot typically consists of a high frequency semicircle and a low frequency spike. In the Nyquist plot for a pure EG based EDLC system there is not a semicircle

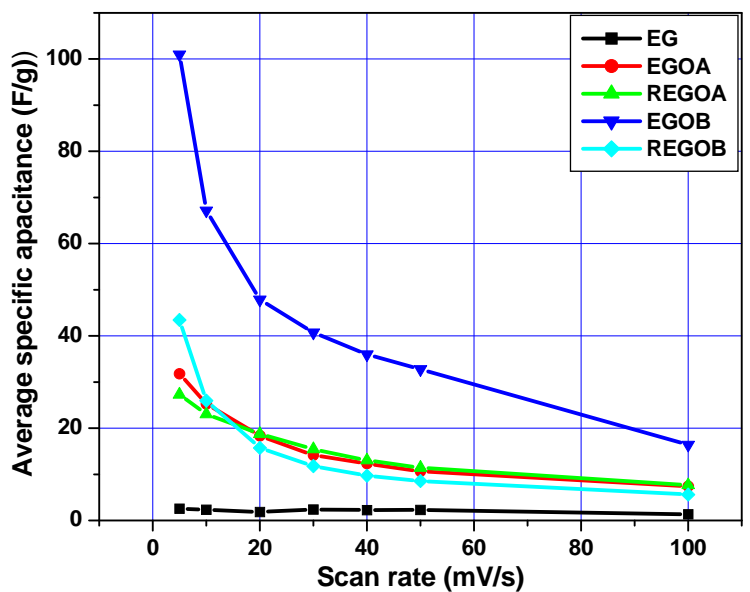

Figure 7. Variation of specific capacitance with scan rates.

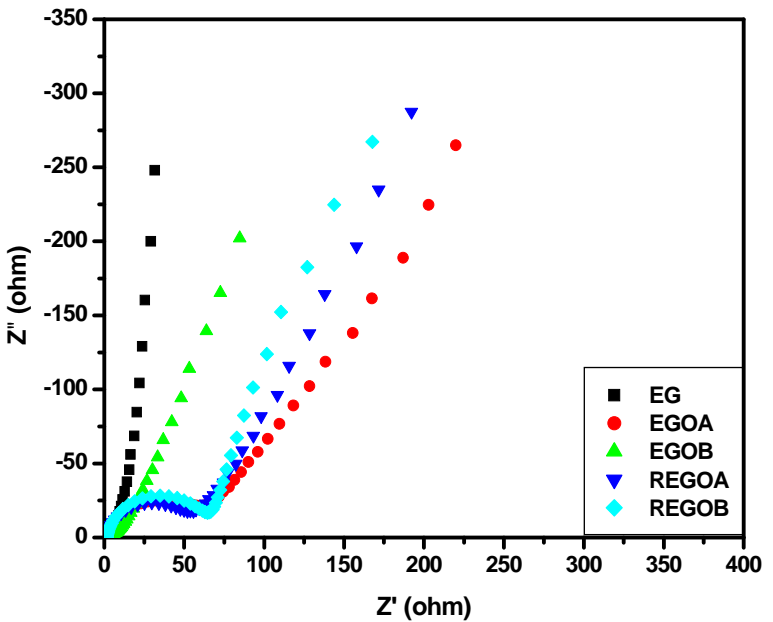

Figure 8. AC impedance spectrum of pure EG, EGOA, EGOB, REGOA, and REGOB samples.

and low frequency spike approximately $90^{\circ}$ to the $\mathrm{x}$ axis.

The magnitude of equivalent series resistance (ESR) is obtained from $\mathrm{x}$-intercept of the Nyquist plot. Constant phase element (CPE) was evaluated by curve fitting the Nyquist plot in $\mathrm{Z}$ view and the values of both ESR and CPE are tabulated in Table 1.

The electrolyte ions cannot penetrate into micropores under high frequencies. Once the phenomenon of trapping of ions occurs in either ion-insertion electrodes or porous metallic electrode, its electrochemical impedance is expected to change dramatically, showing a relatively high resistance in the low-frequency domain, which otherwise i.e., in the absence of trapping would remain small, with the total impedance exhibiting basically a capacitive behavior [30]. The superior capacitive performance at higher frequencies can be ascribed to their hierarchical pore system that favours fast diffusion of electrolyte at high frequencies. It is very likely that the presence of surface oxides may retard the movement of electrolytes 
Table 1. Equivalent series resistance (ESR) and constant phase element (CPE) of all the prepared electrodes.

\begin{tabular}{ccccc}
\hline S. No & $\begin{array}{c}\text { Electrode } \\
\text { material }\end{array}$ & $\begin{array}{c}\text { ESR } \\
(\mathrm{ohm})\end{array}$ & CPE & $\begin{array}{c}\text { Specific } \\
\text { capacitance } \\
\mathrm{Fg}^{-1}\end{array}$ \\
\hline 1 & EG & 1.83 & 0.92 & 11.84 \\
2 & EGOA & 1.68 & 0.62 & 112.59 \\
3 & REGOA & 2.12 & 0.79 & 45.03 \\
4 & EGOB & 1.30 & 0.75 & 146.84 \\
5 & REGOB & 1.28 & 0.75 & 70.24 \\
\hline
\end{tabular}

and thus increase the ohmic resistance of electrolytes along the axial direction of micropores, which would combine with the existence of the distributed capacitance. In addition, surface oxides are strong polar sites that would adsorb water molecules and thus hinder the migration of electrolytes in pores.

The maximum power density of the supercapacitor has been calculated from the low frequency data of the impedance spectra, according to the equation

$$
P_{\max }=V_{i}^{2} / 4 m R
$$

where $V_{\mathrm{i}}$ is the initial voltage, $R$ is the ESR and $m$ is the mass of the electrodes. A maximum power density of 55 $\mathrm{kW} \cdot \mathrm{kg}^{-1}$ was obtained.

\subsection{Galvanostatic Charge/Discharge Tests}

Galvanostatic charge-discharge measurements are comm. only used to test the performance of capacitor. Figure 9 shows the charge/discharge curves of the samples that were obtained at the current density of $20 \mathrm{~mA} \cdot \mathrm{cm}^{-2}$ for EG and $50 \mathrm{~mA} \cdot \mathrm{cm}^{-2}$ EGOA and EGOB.

The specific capacitance is deduced from the slope of the discharge curve using the following equation

$$
C_{S}=I /[(d V / d t) x m]\left(\mathrm{Fg}^{-1}\right)
$$

where $C_{s}$ is the specific capacitance in $\mathrm{Fg}^{-1}$, I is the discharge current in ampere, $\mathrm{dV} / \mathrm{dt}$ is the slope of the discharge curve after the $i R$ drop in $\mathrm{Vs}^{-1}, \mathrm{~m}$ is the mass of the material in one electrode. The specific capacitance of the EG, EGOA, REGOA, EGOB and REGOB samples were $11.84,112.59,45.03,146.84$, and $70.24 \mathrm{Fg}^{-1}$ respectively. The maximum specific capacitance reaches $146 \mathrm{Fg}^{-1}$ for EGOB electrode. The maximum energy storage can be calculated as $20.39 \mathrm{Wh} \cdot \mathrm{kg}^{-1}$ for the same electrode material with $C v_{i} / 2$ where $C$ is the specific capacitance (146 $\left.\mathrm{Fg}^{-1}\right)$ and $V_{i}$ is the initial voltage $(1.0 \mathrm{~V})$.

The charge-discharge profiles of all samples exhibit almost the isosceles triangle curves, which indicate the simulative capacitor with the performance of electrochemical stability and reversibility.

Figure 10 shows the variation of specific capacitance with cycle number for EGOB that shows good stability of

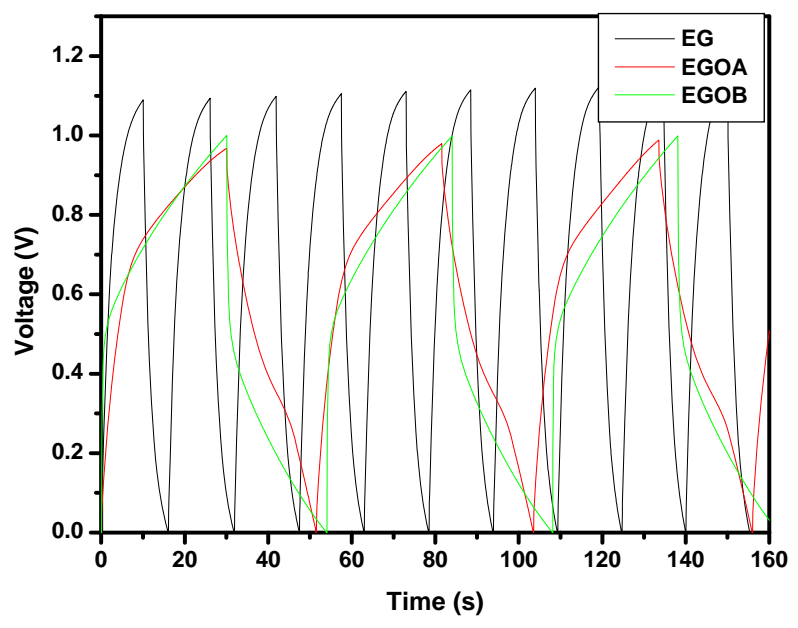

Figure 9. Galvanostatic charge-discharge curves for EG electrodes at a constant current density of $20 \mathrm{~mA} \cdot \mathrm{cm}^{-2}$. and EGOA and EGOB samples at $50 \mathrm{~mA} \cdot \mathrm{cm}^{-2}$.

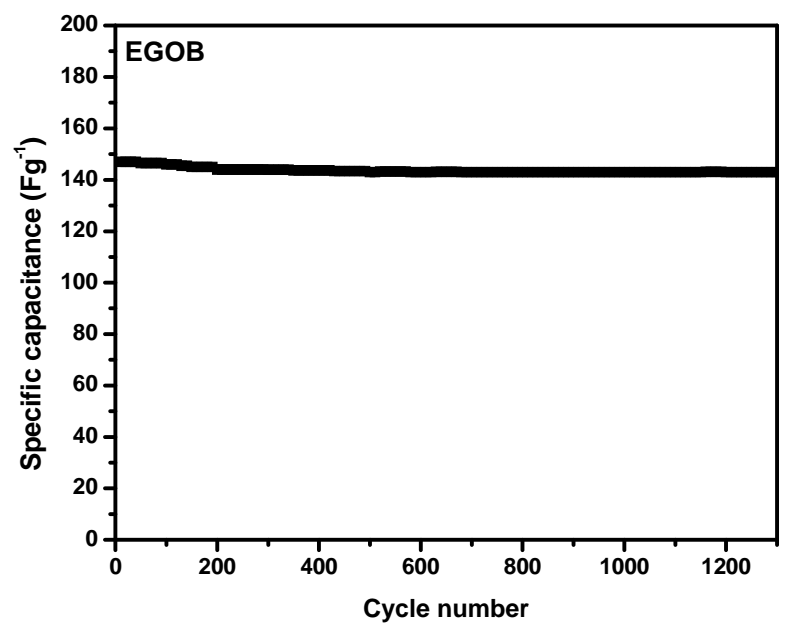

Figure 10. Specific capacitance change as a function of cycle number at a current density of $50 \mathrm{~mA} \cdot \mathrm{cm}^{-2}$.

capacitance over a cycle of 1200 revealing the good lifetime of the electrodes.

\section{Conclusion}

Electrodes prepared from exfoliated graphene oxide with various degree of oxidation were characterized by spectroscopic and electrochemical methods. The XRD pattern of EG and EGO indicates that the distance between the graphene sheets has increased due to the insertion of interplanar groups. The presence of various functional groups present in the materials that contributes to the pseudo capacitance effect was analyzed from the FTIR spectra. The specific capacitance was found to increase with the extent of oxidation, which is in agreement with the results from cyclic voltammetric measurements. The chargedischarge characteristics were also analyzed. The fabricated supercapacitor using exfoliated graphene oxide 
(EGOB) gave a specific capacitance of $146 \mathrm{Fg}^{-1}$ and energy density of $20.39 \mathrm{Wh} \cdot \mathrm{kg}^{-1}$ This work opens up the understanding of graphene via, an electrochemical way. We have employed an easy chemical route to prepare an electrode material with graphene oxide sheets for supercapacitor applications.

\section{Acknowledgements}

The authors would like to acknowledge Dr. G. Sundararajan for his constant support and encouragement. The financial support from DST, Govt of India is acknowledged herewith.

\section{REFERENCES}

[1] B. E. Conway, "Electrochemical Supercapacitors: Scientific Fundamentals and Technological Applications," Kluwer Academic/Plenum Publishers, New York, 1999.

[2] R. Kotz and M. Carlen, "Principles and Applications of Electrochemical Capacitors," Electrochimica Acta, Vol. 45, No. 15-16, 2000, pp. 2483-2498. doi: $10.1177 / 14624740022227908$

[3] A. Burke, "Ultracapacitors: Why, How, and Where Is the Technology," Journal of Power Sources, Vol. 91, No. 1, 2000, pp. 37-50. doi:10.1016/S0378-7753(00)00485-7

[4] "Basic Research Needs for Electrical Energy Storage: Report of the Basic Energy Sciences Workshop on Electrical Energy Storage, 2-4 April 2007," Office of Basic Energy Sciences, Department of Energy, July 2007.

[5] J. Schindall, "The Charge of the Ultracapacitors," IEEE Spectrum, Vol. 44, No. 11, 2007, pp. 42-46. doi:10.1109/MSPEC.2007.4378458

[6] S. Stankovich, D. A. Dikin, G. H. B. Dommett, K. M. Kohlhaas, E. J. Zimney, E. A. Stach, R. D. Piner, S. T. Nguyen and R. S. Ruoff, "Graphene-Based Composite Materials," Nature, Vol. 442, No. 7100, 2006, pp. 282286. doi:10.1038/nature04969

[7] D. A. Dikin, S. Stankovich, E. J. Zimney, R. D. Piner, G. H. B. Dommett, G. Evmenenko, S. T. Nguyen and R. S. Ruoff, "Preparation and Characterization of Graphene Oxide Paper," Nature, Vol. 448, No. 7152, 2007, pp. 457460. doi: $10.1038 /$ nature 06016

[8] J. S. Bunch, A. M. van der Zande, S. S. Verbridge, I. W Frank, D. M. Tanenbaum, J. M. Parpia, H. G. Craighead and P. L. McEuen, "Electromechanical Resonators from Graphene Sheets," Science, Vol. 315, No. 58, 2007, pp. 490-493. doi:10.1126/science. 1136836

[9] S. Watcharotone, D. A. Dikin, S. Stankovich, R. Piner, I. Jung, G. H. B. Dommett, G. Evmenenko, S. E. Wu, S. F. Chen, C. P. Liu, S. T. Nguyen and R. S. Ruoff, "Graphene-Silica Composite Thin Films as Transparent Conductors," Nano Letters, Vol. 7, No. 7, 2007, pp. 18881892. doi:10.1021/n1070477+

[10] C. Gomez-Navarro, R. T. Weitz, A. M. Bittner, M. Scolari, A. Mews, M. Burghard and K. Kern, "Electronic Transport Properties of Individual Chemically Reduced Graphene Oxide Sheets," Nano Letters, Vol. 7, No. 11,
2007, pp. 3499-3503. doi:10.1021/n1072090c

[11] F. Schedin, A. K. Geim, S. V. Morozov, E. W. Hill, P. Blake, M. I. Katsnelson and K. S. Novoselov, "Detection of Individual Gas Molecules Adsorbed on Graphene," Nature Materials, Vol. 6, No. 9, 2007, pp. 652-655. doi:10.1038/nmat1967

[12] A. A. Balandin, S. Ghosh, W. Z. Bao, I. Calizo, D. Teweldebrhan, F. Miao and C. N. Lau, "Superior Thermal Conductivity of Single-Layer Graphene," Nano Letters, Vol. 8, No. 3, 2008, pp. 902-907. doi:10.1021/n10731872

[13] C. Gomez-Navarro, M. Burghard and K. Kern, "Elastic Properties of Chemically Derived Single Graphene Sheets," Nano Letters, Vol. 8, No. 7, 2008, pp. 2045-2049. doi:10.1021/n1801384y

[14] X. Wang, L. J. Zhi and K. Mullen, "Transparent, Conductive Graphene Electrodes for Dye-Sensitized Solar Cells," Nano Letters, Vol. 8, No. 1, 2008, pp. 323-327. doi:10.1021/n1072838r

[15] D. Li, M. B. Muller, S. Gilje, R. B. Kaner and G. G. Wallace, "Processable Aqueous Dispersions of Graphene Nanosheets," Nature Nanotechnology, Vol. 3, No. 2, 2008, pp. 101-105. doi:10.1038/nnano.2007.451

[16] S. R. C. Vivekchand, C. S. Rout, K. S. Subrahmanyam, A. Govindaraj and C. N. R. J. Rao, "Graphene-Based Electrochemical Supercapacitors," Chemistry and Materials Science, Vol. 120, No. 1, 2008, pp. 9-13. doi:10.1007/s12039-008-0002-7

[17] K. S. Subrahmanyam, S. R. C. Vivekchand, A. Govindaraj and C. N. R. Rao, "A Study of Graphenes Prepared by Different Methods: Characterization, Properties and Solubilization," Journal of Materials Chemistry, Vol. 18, No. 13, 2008, pp. 1517-1523. doi:10.1039/b716536f

[18] S. M. Paek, E. Yoo and I. Honma, "Enhanced Cyclic Performance and Lithium Storage Capacity of $\mathrm{SnO}_{2} / \mathrm{Gra}$ phene Nanoporous Electrodes with Three-Dimensionally Delaminated Flexible Structure," Nano Letters, Vol. 9, No. 1, 2009, pp. 72-75. doi:10.1021/n1802484w

[19] S. D. Meryl, P. Sungjin, Z. Yanwu, A. Jinho and R. S. Rodney, "Graphene-Based Ultracapacitors," Nano Letters, Vol. 8, No. 10, 2008, pp. 3498-3502. doi:10.1021/n1802558y

[20] T. Ramanathan, A. A. Abdala, S. Stankovich, D. A. Dikin, M. Herrera-Alonso, R. D. Piner, D. H. Adamson, H. C. Schniepp, X. Chen, R. S. Ruoff, S. T. Nguyen, I. A. Aksay, R. K. Prudhomme and L. C. Brinson, "Functionalized Graphene Sheets for Polymer Nanocomposites," Nature Nanotechnology, Vol. 3, No. 6, 2008, pp. 327-331. doi:10.1038/nnano.2008.96

[21] E. Yoo, J. Kim, E. Hosono, H. Zhou, T. Kudo and I. Honma, "Large Reversible Li Storage of Graphene Nanosheet Families for Use in Rechargeable Lithium Ion Batteries," Nano Letters, Vol. 8, No. 8, 2008, pp. 2277-2282. doi:10.1021/n1800957b

[22] M. D. Stoller, S. J. Park, Y. W. Zhu, J. H. An and R. S. Ruoff, "Graphene-Based Ultracapacitors," Nano Letters, Vol. 8, No. 10, 2008, pp. 3498-3502. doi:10.1021/n1802558y

[23] D.-W. Wang, F. Li, J. P. Zhao, W. C. Ren, Z.-G. Chen, J. 
Tan, Z.-S. Wu, I. Gentle, G. Q. Lu and H.-M. Cheng, "Fabrication of Graphene/Polyaniline Composite Paper via in Situ Anodic Electropolymerization for High-Performance Flexible Electrode," ACS Nano, Vol. 3, No. 7, 2009, pp. 1745-1752. doi:10.1021/nn900297m

[24] J. Yan, T. Wei, Z. J. Fan, W. Z. Qian, M. L. Zhang, X. D. Shen and F. Wei, "Preparation of Graphene Nanosheet/Carbon Nanotube/Polyaniline Composite as Electrode Material for Supercapacitors," Journal of Power Sources, Vol. 195, No. 9, 2009, pp. 3041-3045.

[25] M. Kaempgen, K. Candace, J. Chan, Y. C. Ma and G. Gruner, "Printable Thin Film Supercapacitors Using Single-Walled Carbon Nanotubes," Nanoletters, Vol. 9, No. 5, 2009, pp. 1872-1876. doi:10.1021/n18038579

[26] W. S. Hummers Jr. and R. E. Offeman, "Preparation of Graphitic Oxide," Journal of the American Chemical Society, Vol. 80, No. 6, 1958, p. 1339. doi:10.1021/ja01539a017
[27] D. Hulicova, J. Yamashita, Y. Soneda, H. Hatori and M. Kodama, "Supercapacitors Prepared from MelamineBased Carbon," Chemistry Materials, Vol. 17, No. 5, 2005, pp. 1241-1247. doi:10.1021/cm049337g

[28] D. Hulicova, M. Kodama and H. Hatori, "Electrochemical Performance of Nitrogen-Enriched Carbons in Aqueous and Non-Aqueous Supercapacitors," Chemistry Materials, Vol. 18, No. 9, 2006, pp. 2318-2326. doi:10.1021/cm060146i

[29] G. Lota, B. Grzyb, H. Machnikowska, J. Machnikowski and E. Frackowiak, "Effect of Nitrogen in Carbon Electrode on the Supercapacitor Performance," Chemical Physics Letters, Vol. 404, No. 1-3, 2005, pp. 53-58. doi:10.1016/j.cplett.2005.01.074

[30] G. Lota, K. Lota and E. Frackowiak, "Nanotubes Based Composites Rich in Nitrogen for Supercapacitor Application," Electrochemistry Communications, Vol. 9, No. 7, 2007, pp. 1828-1832. doi:10.1016/j.elecom.2007.04.015 